https://helda.helsinki.fi

Comment : Critical Questions for Affect Control Theory

Salmela, Mikko

2014-04

Salmela , M 2014 , ' Comment : Critical Questions for Affect Control Theory ' , Emotion review , vol. 6 , no. 2 , pp. 138-139 . https://doi.org/10.1177/1754073913512002

http://hdl.handle.net/10138/233172

https://doi.org/10.1177/1754073913512002

acceptedVersion

Downloaded from Helda, University of Helsinki institutional repository.

This is an electronic reprint of the original article.

This reprint may differ from the original in pagination and typographic detail.

Please cite the original version. 
Emotion review 6(2):138-139

ISSN: $1754-0739$

DOI: $10.1177 / 1754073913512002$

Post-print / Accepted author manuscript

Critical Comments to Affect Control Theory 1

Published 2014

Running Head: Critical Questions to Affect Control Theory

Comment: Critical Questions to Affect Control Theory

Mikko Salmela

University of Helsinki

Correspondence to:

Mikko Salmela

University of Helsinki

Helsinki Collegium for Advanced Studies

P.O.Box 24 (Fabianinkatu 24A)

00014 University of Helsinki, FINLAND

Phone: +358-9-191 23511

Fax: +358-9-191 24509

Email: mikko.salmela@helsinki.fi 


\begin{abstract}
Affect control theory (ACT) is a sociological theory developed for modeling and predicting emotions and social behaviors in social interaction. In this commentary, I identify a few potential problems in the theory, as presented in the target article and elsewhere, and in its suggested compatibility with other major emotion theories. The first problem concerns ACT's capacity to model emotion generation insofar as emotions have nonconceptual content. The second problem focuses on the limits of modeling interaction on the basis of fixed affective meanings of identities. Finally, ACT has problems with explaining the dynamic change of affective meanings, given its tenets that people seek to maintain the established affective meanings of social roles and situations and deflections are not expressed in behavior but compensated by identity-confirming behavior.
\end{abstract}

Keywords: emotional content, affective meaning, stability and change

Word count (excluding abstract and keywords): 909 words 
Critical Comments to Affect Control Theory 3

\section{Comment: Critical Questions to Affect Control Theory}

Mikko Salmela

Affect control theory (ACT) is a sociological theory developed for modeling and predicting emotions and social behaviors in social interaction. In this commentary, I identify a few potential problems in the theory, as presented in the target article and elsewhere, and in its suggested compatibility with other major emotion theories.

Rogers et al. (2013,000) claim that ACT is compatible with appraisal theories on the causation of emotions. The authors identify the relationship between individual appraisals and culturally shared affective meanings as an area for cross-disciplinary research that is capable of "elucidating the importance of the social for individual, emotion-generating appraisal processes". My reservations about this idea relate to the nature of emotional processing. ACT is a theory about affective meanings of concepts. Therefore, its applicability to emotion-generating appraisal processes seems to limit to those human emotions that have conceptual content. Yet we also have emotions with nonconceptual content whose automatic appraisals emerge from mere perceptual cues and are capable of contradicting our conceptual appraisals. Appraisal theories respond to this problem by identifying the content of emotional appraisals in functional terms (Moors, 2009). However, this option seems foreclosed from ACT that models appraisal as computation of affective meanings of concepts. This problem undermines ACT's capacity to model emotion generation insofar as emotions have nonconceptual content.

A second problem associates with the content of affective meanings. ACT theorists believe that it is possible to determine fixed meanings of identities and that the 
Critical Comments to Affect Control Theory 4

affective consequences of interaction can be predicted on the basis of the agents' identities and the type of interaction. However, the affective meanings of some identities appear to be relational in the sense that they depend on the interactors and not merely on relative differences between the fixed meanings of their identities. This is the case with hierarchical organizations, such as the army. A drill-sergeant is all-powerful and highly active in relation to the rookies but similar to them in relation to the division commander. Even if differences between the affective meanings of these identities can perhaps be represented in terms of mathematical values, the mathematical differences hardly capture the qualitative differences and their implications in real interactions.

A third problem concerns the stability and change of affective meanings. Referring to Robinson and Smith-Lovin (1992), the authors claim that "people strive to maintain salient identities even when they carry negative meanings and lead to the experience of negative emotions" (Rogers et al., 2013, 000). However, the plausibility of this claim seems to depend on people's acquiescence in the affective meaning of their identity. If people with stigmatized identities realize that the negative affective meanings of their identities result from a history of oppression, as is the case with women, homosexuals, and African Americans, for instance, then - instead of seeking identityconfirming feedback - these individuals tend to resent people who treat them in terms of those identities and seek to redefine their identities in social interaction. Indeed, Britt and Heise (2000) highlight consciousness raising in the transformation of shame into pride in homosexuals' social movements. However, they do not invoke ACT principles, so I interpret this evidence in favor of my point. 
Critical Comments to Affect Control Theory 5

More generally, adherents of ACT argue that the theory can explain both people's motivation to maintain affective meanings in social interaction and the dynamic change of meanings as the result of large deflections from established meanings. Yet it is not clear why large deflections occur in the first place and, secondly, how they can contribute to change if maintenance of established meanings is the default mode and deflections are not expressed in behavior but compensated by identity-confirming behavior whenever they happen. ACT claims that emotions inform and identities motivate, whereas other emotion theories suggest that emotions have both functions (e.g. MacKinnon, 1994). I believe that this dispute can be adjudicated by a distinction between expressive and instrumental behavior. Emotions motivate expressive behaviors that inform both the subject and others about the subject's interpretation of the situation. These expressions influence social interaction thereby counting as behavior. Expressions that deflect from established identities give rise to the need for identity-confirming instrumental behavior. However, expressive and instrumental behaviors seem to blur when expressions are consistent with one's identity. When I snap at my colleague in response to her derogatory comment, do I act out of my anger or my offended identity - or both?

In spite of these reservations, I am sympathetic to the authors' idea of offering ACT as a conceptual and methodological "hub" for emotion research and theorizing at different levels of analysis. Thus, in my theorizing on collective emotions, I find the authors' proposal that shared affective meanings allow individuals to generate appraisals and emotions more efficiently a plausible hypothesis for explaining the effortless elicitation of collective emotions - insofar as they have conceptual content. 
References

Britt, L. \& Heise. D.R. (2000) From shame to pride. In S. Stryker, T.J. Owens, and R.W. White (eds), Self, Identity, and Social Movements (pp. 252-268). Minneapolis: University of Minnesota Press.

Moors, A. (2009). Theories of emotion causation: A review. Cognition and Emotion, 23, 625-662.

MacKinnon, N. (1994). Symbolic Interaction as Affect Control. New York: State University of New York Press.

Robinson, D.T. \& Smith-Lovin, L. (1992) Selective interaction as a strategy for identity maintenance: an affect control model. Social Psychological Quarterly, 55 (1), 12-28.

Rogers, K., Schröder, T. \& von Scheve, C. (2013). Dissecting the sociality of emotion: a multi-level approach. Emotion Review $X(X)$, 000-000. 